\title{
Retracted: Mechanical and Thermal Stability Properties of Modified Rice Straw Fiber Blend with Polycaprolactone Composite
}

\author{
Journal of Nanomaterials \\ Received 15 January 2015; Accepted 15 January 2015 \\ Copyright (C) 2015 Journal of Nanomaterials. This is an open access article distributed under the Creative Commons Attribution \\ License, which permits unrestricted use, distribution, and reproduction in any medium, provided the original work is properly \\ cited.
}

The paper titled "Mechanical and Thermal Stability Properties of Modified Rice Straw Fiber Blend with Polycaprolactone Composite" [1], published in Journal of Nanomaterials, has been retracted as it was found to have violated the journal's policy against citation manipulation.

\section{References}

[1] R. Khandanlou, M. B. Ahmad, K. Shameli, M. Z. Hussein, N. Zainuddin, and K. Kalantari, "Mechanical and thermal stability properties of modified rice straw fiber blend with polycaprolactone composite," Journal of Nanomaterials, vol. 2014, Article ID 675258, 9 pages, 2014. 


\title{
Mechanical and Thermal Stability Properties of Modified Rice Straw Fiber Blend with Polycaprolactone Composite
}

\author{
Roshanak Khandanlou, ${ }^{1}$ Mansor B. Ahmad, ${ }^{1}$ Kamyar Shameli, ${ }^{1}$ Mohd Zobir Hussein, \\ Norhazlin Zainuddin, ${ }^{1}$ and Katayoon Kalantari ${ }^{1}$ \\ ${ }^{1}$ Department of Chemistry, Faculty of Science, Universiti Putra Malaysia (UPM), 43400 Serdang, Selangor, Malaysia \\ ${ }^{2}$ Material Synthesis and Characterization Laboratory, Institute of Advanced Technology (ITMA), \\ Universiti Putra Malaysia (UPM), 43400 Serdang, Selangor, Malaysia
}

Correspondence should be addressed to Roshanak Khandanlou; roshanak_bch@yahoo.com, Mansor B. Ahmad; mansorahmad@gmail.com and KamyarShameli; kamyarshameli@gmail.com

Received 8 April 2014; Revised 12 June 2014; Accepted 12 June 2014; Published 16 July 2014

Academic Editor: Lavinia Balan

Copyright (C) 2014 Roshanak Khandanlou et al. This is an open access article distributed under the Creative Commons Attribution License, which permits unrestricted use, distribution, and reproduction in any medium, provided the original work is properly cited.

The goal of this study was to investigate the effect of modified rice straw (ORS) on the mechanical and thermal properties of modified rice straw/polycaprolactone composites (ORS/PCL-Cs). The composites (Cs) of polycaprolactone (PCL) with ORS were successfully synthesized using the solution-casting method. The RS modified with octadecylamine (ODA) as an organic modifier. The prepared composites were characterized by using powder X-ray diffraction (XRD), thermogravimetric analysis (TGA), scanning electron microscopy (SEM), and Fourier transforms infrared spectroscopy (FT-IR), and mechanical properties were investigated. Composites of ORS/PCL showed superior mechanical properties due to greater compatibility of ORS with PCL. The XRD results showed that the intensity of the peaks decreased with the increase of ORS content from 1.0 to 7.0 wt.\% in comparison with PCL peaks. Tensile measurement showed an increase in tensile modulus but a decrease in tensile strength and elongation at break as the ORS contents are increased from 1.0 to $7.0 \mathrm{wt}$.\%; on the other hand, tensile strength was improved with the addition of $5.0 \mathrm{wt} . \%$ of ORS. Thermal stability was decreased with the increase of ORS contents. SEM micrograph indicated good dispersion of ORS into the matrix, and FT-IR spectroscopy showed that the interaction between PCL and ORS is physical interaction.

\section{Introduction}

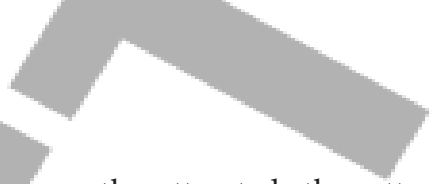

Natural fibers have recently attracted the attention of researchers for use as reinforcement material for different types of polymer matrix due to its advantages over other established components. They are completely biodegradable, abundantly available, and renewable [1]. Among the different agricultural straw, rice straw could be very interesting material as filler in biodegradable polymer composites due to their good thermal stability compared with other agricultural wastes. The resistance of rice straw to bacterial decomposition makes this material suitable as a filler material in the construction of composites. Furthermore, a high content of silica (up to 20\%) represents a potential additional benefit over the flame retardant when used in the construction industry [2]. It represents about $45 \%$ of the volume of rice production, which produces the greatest amount of crop residues. Rice straw has the most amount of cellulose from agricultural crop residues because its composition is cellulose (38.3\%), hemicelluloses (31.6\%), and lignin (11.8\%).

Polycaprolactone (PCL) is one of the most attractive and commonly used biodegradable polyesters [3]. It can be used in various biomedical applications such as scaffolds for tissue engineering applications and for the controlled release of drugs [4]. Poly ( $\varepsilon$-caprolactone) is a semicrystalline polymer with a crystallinity degree of approximately $50 \%$. PCL is regularly achieved through ring opening process (ROP) of $\varepsilon$ caprolactone in the presence of metal alkoxides (aluminium isopropoxide, tin octoate, etc.).

Flexibility, biodegradability, low glass transition temperature $\left(\mathrm{T}_{g}\right)$ of $\left(-61^{\circ} \mathrm{C}\right)$, melting point of $\left(65^{\circ} \mathrm{C}\right)$, high elongation at break, low modulus, relatively high price, and rather long 
biodegradability cycle are known as particular characteristics of PCL [5].

The synthesis of polymer nanocomposite is a basic visible feature of polymer nanotechnology [6-12]. Nanocomposites are two phase components where one of the phases is at least one dimension in 1 to 100 nanometer [13-21]. Nanocomposites have higher thermal and mechanical properties in comparison with other composites and also they have better recyclability and low weight $[22,23]$.

Polymer composites are prepared using polymers and natural or synthetic fibers that are compatible [24]. The usual polar and also hydrophilic fibers have inherently lower compatibility with nonpolar and hydrophobic polymer matrices, as well as the incompatibility leading to problems in the processing and properties of composite materials. Hydrogen bonds can be formed between the hydrophilic fibers, so the fibers will have tendency to agglomerate into bundles and distributed unevenly throughout the polymer matrix which are nonpolar during the process of compounding $[25,26]$.

In this work, ORS/PCL-Cs were prepared with different percentages of rice straw $(1.0,3.0,5.0$, and $7.0 \mathrm{wt} . \%)$ at room temperature in dichloromethane using polycaprolactone as a polymer and modified rice straw which modified with octadecylamine by solution-casting method.

\section{Experimental Procedure}

2.1. Materials. All chemical agents used in this study were of analytical grade and used without further purification. Rice straw was obtained from local farm (Bukit Tinggi, Kedah, Malaysia). Polycaprolactone (PCL), (Sigma- Aldrich, USA). Material used for the modification of rice straw is octadecylamine (ODA) (Merk, Germany). Dichloromethane $\left(\mathrm{CH}_{2} \mathrm{Cl}_{2}\right)$ is used as a solvent (Qrec, Malaysia). All glasswares used in experimental procedures were cleaned in a fresh solution of $\mathrm{HNO}_{3} / \mathrm{HCl}(3: 1, \mathrm{v} / \mathrm{v})$, washed thoroughly with double distilled water, and dried before use.

2.2. Modification of Rice Straw. Rice straw was used as filler in this research. (5.0 g) RS was dispersed into $150 \mathrm{~mL}$ of $\left(80^{\circ} \mathrm{C}\right)$ hot distilled water with continuous agitation, with the speed of mechanical stirrer adjusted at $200 \mathrm{rpm}$ for one hour. At the same time, in a separate beaker, hot distilled water with the temperature of $80^{\circ} \mathrm{C}$ was added to a $2.7 \mathrm{~g} \mathrm{ODA}$, stirring at the speed of $200 \mathrm{rpm}$ for an hour. Then, the two above mentioned solutions were combined and put under stirring at the same speed and temperature for an hour in order to flocculate the RS. In the next step, the resulted solution was filtered carefully many times as minimum one time for each gram of RS in content. After each filtering cycle, the precipitate was collected, washed with hot distilled water, and stirred in that water at the speed of $200 \mathrm{rpm}$.

2.3. Preparation of Modified Rice Straw/Polycaprolactone Composites. For the synthesis of ORS/PCL-Cs, different ratios of ORS (1.0, 3.0, 5.0, and 7.0 wt.\%) were suspended in certain amount of dichloromethane with stirring for half an hour, and then $5 \mathrm{~g}$ PCL was dissolved in $50 \mathrm{~mL}$ dichloromethane; then ORS suspension was added slowly to PCL solution with vigorous stirring. After addition of the ORS suspension, stirring was continued for a further another hour to get the ORS well dispersed in the principal composite. The suspensions were finally poured in petri dishes and kept for 2 days until it was completely dry. Finally the solidified films are obtained, having a thickness of about $0.5 \mathrm{~mm}$. All the experiments were performed at room temperature.

2.4. Characterization Methods and Instruments. In order to investigate the morphology of RS, ORS, and ORS/PCLCs, cross section photos were taken with SEM (LEO1455 SEM, LEO \& Leica factory, Cambridge, UK). The powder $\mathrm{X}$-ray diffraction (XRD) with $\mathrm{Cu} \mathrm{K} \alpha$ radiation was used to measure the crystallinity of samples. Thermal gravimetric analysis (TGA) and differential thermal gravimetric (DTG) were used to study thermal behavior of samples. Fourier transform infrared spectroscopy (FT-IR) in the range of 400$4000 \mathrm{~cm}^{-1}$ was used in order to study the structures of the RS, ORS, ODA, PCL, and ORS/PCL-Cs. FT-IR spectra were recorded by use of the Series 100 PerkinElmer FT-IR 1650 spectrophotometer. Tensile strength, Young's modulus, and elongation at break were measured using Instron Universal Testing Machine model INSTRON 4302 at constant crosshead speed of $5 \mathrm{~mm} / \mathrm{min}$ and $1 \mathrm{kN}$ load. Four samples were used for the tensile test and the average values were calculated from five runs for each sample.

\section{Results and Discussion}

Figure 1 shows the X-ray diffraction (XRD) pattern of RS, ORS, PCL, and ORS/PCL-Cs in different ratios of ORS (1.0, 3.0, 5.0, and $7.0 \mathrm{wt} . \%)$. The SEM results for RS, ORS, and ORS/PCL-Cs are shown in Figures 2 and 3, respectively. The SEM images for ORS/PCL-Cs show good dispersion of ORS in the PCL. FT-IR analysis of prepared composites revealed that RS modified successfully, and ORS has good dispersion into the matrix (Figure 5). The mechanism of the interaction of PCL with RS showed that the interaction was a physical interaction (Figure 6). TGA analysis indicated that thermal stability decreased with increasing rice straw fiber content (Figure 7). Tensile measurement shows that with increasing ORS content the tensile strength and elongation at break gradually decrease and tensile modulus improves with increasing ORS content (Figure 8).

3.1. Powder X-Ray Diffraction Analysis. By a comparison of the XRD patterns of the neat RS and ORS, it shows that the diffraction peak in ORS is sharper and narrower than RS, indicating the interaction of alkyl ammonium with the RS (Figure 1(a)); the sharper diffraction peak exhibits higher crystallinity degree in the ORS; this increase may be due to the removal of some RS amorphous constituents, and thereby increased the presence of crystalline cellulose [27]; also the diffraction peak in ORS $\left(2 \theta=21.67^{\circ}\right)$ shifts to lower angle compared with neat RS $\left(2 \theta=22.20^{\circ}\right)$ where it shows the modification of RS. Fiber with high crystallinity can improve the mechanical properties of the composites. 


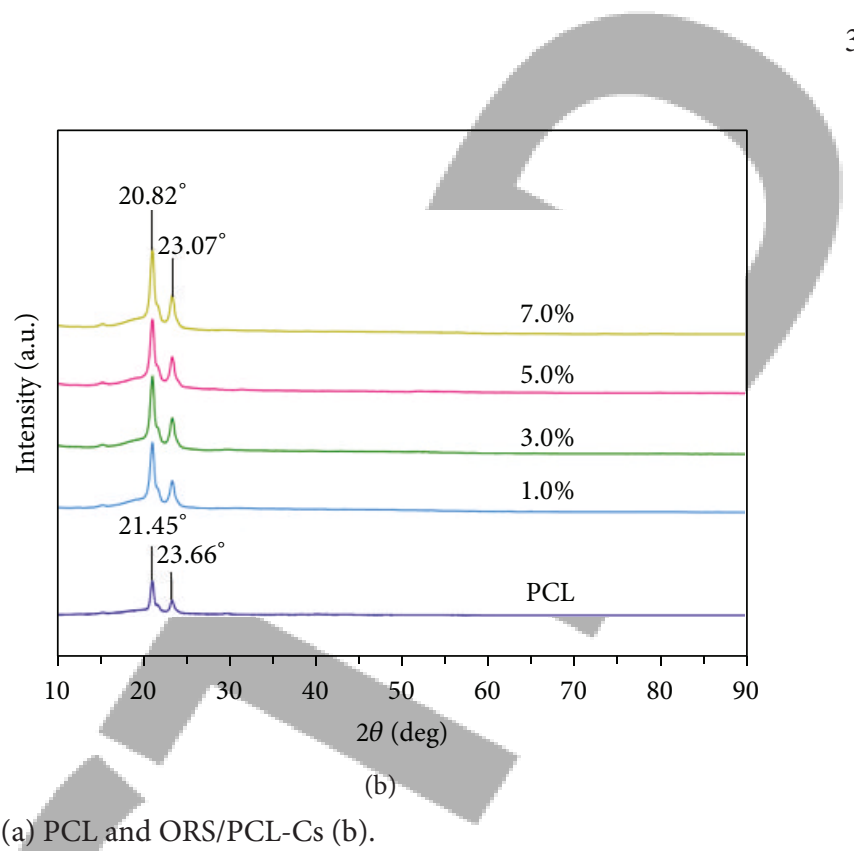

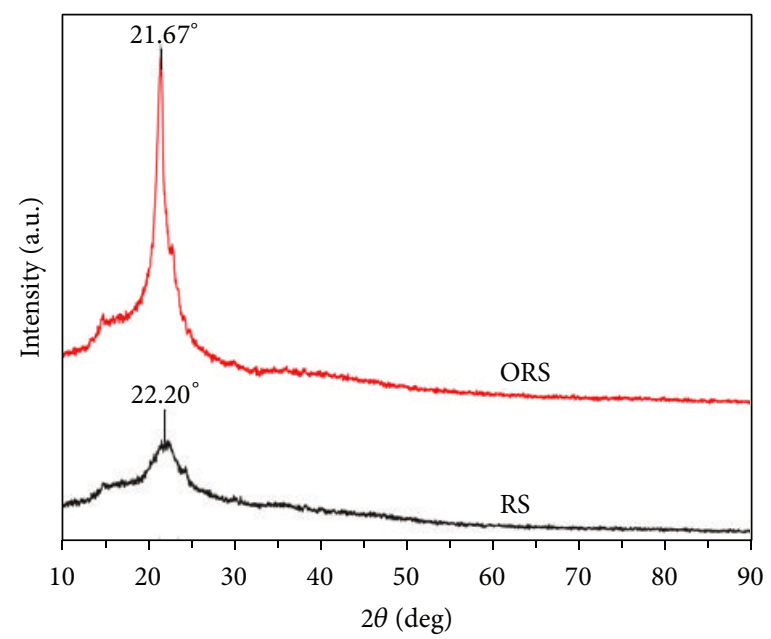

(a)

FIgURE 1: XRD of RS and ORS (a) PCL and ORS/PCL-Cs (b).

The XRD pattern of PCL (Figure 1(b)) shows diffraction peak in $2 \theta=21.45^{\circ}$ and $23.66^{\circ}$; after incorporation of ORS within PCL the diffraction peak of all ORS/PCLCs had shifted to lower value of $2 \theta$ angle, related to the formation of composites. The result shows that the intensity of the diffraction peak in ORS/PCL-Cs decreases with the increasing of ORS content (Figure 1(b)). PCL chain as the major component of the blend, the position of crystalline peak was almost similar to that of the PCL, so it shows that the PCL covers the RS and the peaks of RS could not appear in the XRD pattern.

\subsection{Morphology}

3.2.1. Scanning Electron Microscopy. Figures 2 and 3 show the surface morphology images of RS, ORS, and ORS/PCLCs, respectively. Figure 4 shows electrooptical microscopy (EOM) images of ORS/PCL-Cs. Figure 2 shows SEM micrographs of neat rice straw and rice straw after modification with ODA. It shows that modification causes the ORS to be more homogeneous compared to the neat RS. The SEM micrographs of the ORS/PCL-Cs (Figure 3) show effect of ORS on the surface of composites. It can be seen good dispersion of ORS into the matrix and the fiber did not agglomerate when modifier was used resulting in ORS/PCLCs possessing higher interfacial adhesion and smoother surface. The ORS/PCL-Cs 5.0 wt.\% (Figure 3(c)) demonstrated more homogeneous adhesion of ORS in the ORS/PCL-Cs. The improve in interfacial adhesion was because of the similar hydrophobicity of the two components, which are permitted for the formation of both branched and crosslinked macromolecules and avoided unfavorable hydrogen bonding in the ORS.

Furthermore, according to EOM images (Figure 4), the dispersion of ORS in PCL matrix is improved with the increase of loading percentages of ORS; also the amount of ORS which shows better dispersion in the PCL is increased up to $5.0 \mathrm{wt} \%$ (Figures $4(\mathrm{a})-4(\mathrm{c})$ ); in $7 \mathrm{wt} . \%$ of ORS the scattering of ORS is not good in PCL matrix.
The structure of ORS/PCL-Cs confirmed that, in the composite with $5.0 \mathrm{wt} . \%$ ORS, the external surface of composite becomes spherulitic morphology, more shining, and the ORS is more homogeneous compared with other percentages loading of ORS, which was also in line with the observation of the SEM results. From SEM and EOM images results the optimum percentage loading of ORS in PCL is $5.0 \mathrm{wt} . \%$ and the mechanical properties of ORS/PCL-Cs confirmed this result.

3.3. FT-IR Chemical Analysis. Figures 5(a) and 5(b) show the FT-IR spectra of RS, ODA, ORS, PCL, and ORS/PCL-Cs with different ratios of ORS. In the FT-IR spectrum of neat RS Figure 5(a), the absorption peaks at $3377 \mathrm{~cm}^{-1}$ and $2933 \mathrm{~cm}^{-1}$ are ascribed to stretching vibrations of $-\mathrm{OH}$ groups and the $\mathrm{C}-\mathrm{H}$ stretching, respectively [28]. The smaller shoulder peak at $1735 \mathrm{~cm}^{-1}$ in the RS is attributed to the aliphatic esters in lignin or hemicelluloses. The intense band at $1646 \mathrm{~cm}^{-1}$ is assigned to olefinic $\mathrm{C}=\mathrm{C}$ stretching vibration [29]. The peak at $1444 \mathrm{~cm}^{-1}$ is ascribed to the aromatic $\mathrm{C}=\mathrm{C}$ stretch of aromatic vibration in bound lignin [28]. The absorbance peaks in the $1376-1363 \mathrm{~cm}^{-1}$ originate from $\mathrm{C}-\mathrm{H}$ bending [30]. The region of $1200-1000 \mathrm{~cm}^{-1}$ represents $\mathrm{C}-\mathrm{O}$ stretch and deformation bands in cellulose, lignin, and residual hemicelluloses [31]. The peak observed in region of $890-260 \mathrm{~cm}^{-1}$ corresponds to the glycoside linkages deforming with ring vibration and $\mathrm{OH}$ bending [32]. In the FT-IR spectrum of ODA two intense bonds at 2915 and $2849 \mathrm{~cm}^{-1}$ are assigned to $-\mathrm{CH}_{3}$ and $-\mathrm{CH}_{2}$ stretching. The peak at 3170 to $3331 \mathrm{~cm}^{-1}$ is attributed to amino group.

In the FT-IR spectrum of ORS Figure 5(a), two new intense bands at 2917 and $2851 \mathrm{~cm}^{-1}$ are assigned to the $-\mathrm{CH}_{3}$ stretching and $-\mathrm{CH}_{2}$ stretching and the peak at $3347 \mathrm{~cm}^{-1}$ is related to $-\mathrm{OH}$ and $-\mathrm{NH}$ groups that overlapped with each other, indicating the RS modified successfully. This result attributing to the interaction of hydrogen bonds possibly formed between amino group in ODA and hydroxyl group in RS. After modification of fiber, the $-\mathrm{OH}$ stretching is 


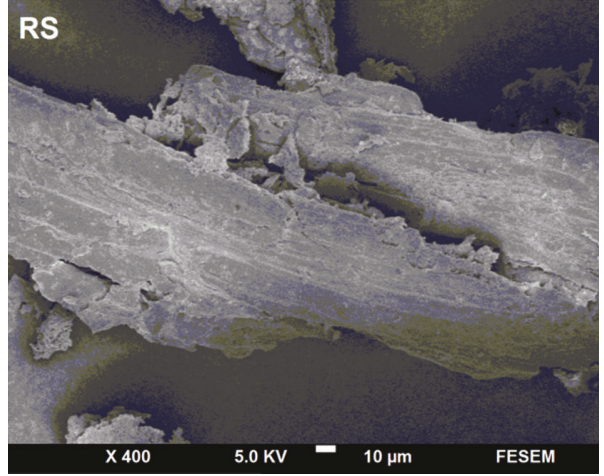

(a)

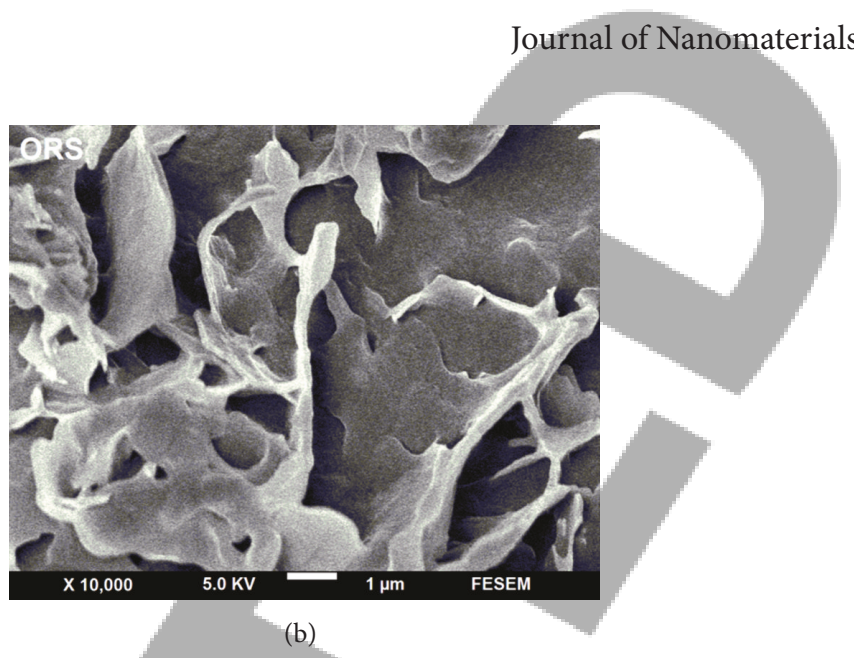

(b)

FIGURE 2: Scanning electron microscopy micrographs of RS and ORS (a), (b), respectively.

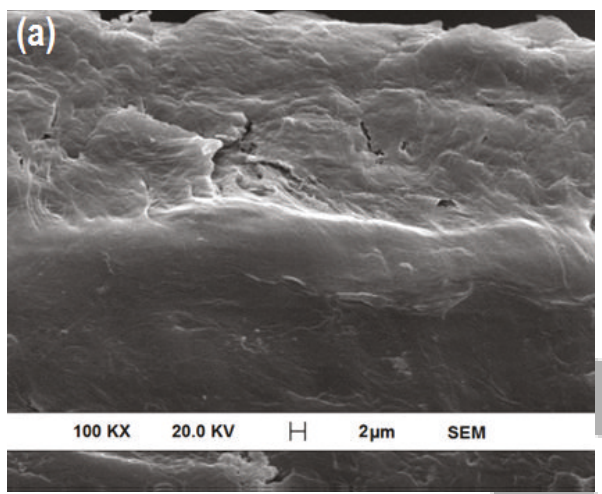

(a)

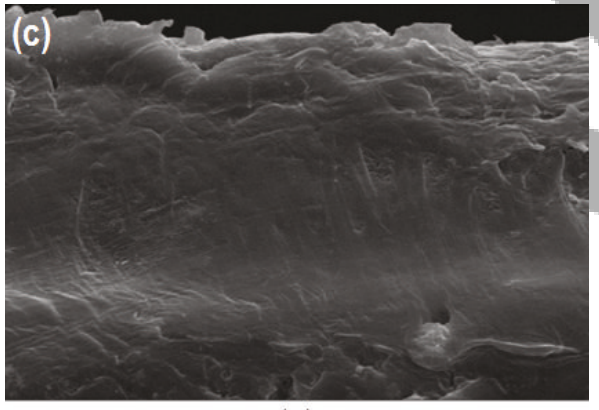

$100 \mathrm{KX} 20.0 \mathrm{KV} \quad \mapsto \quad 3 \mu \mathrm{m} \quad \mathrm{SEM}$

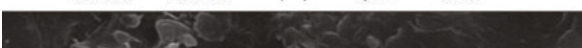

(c)

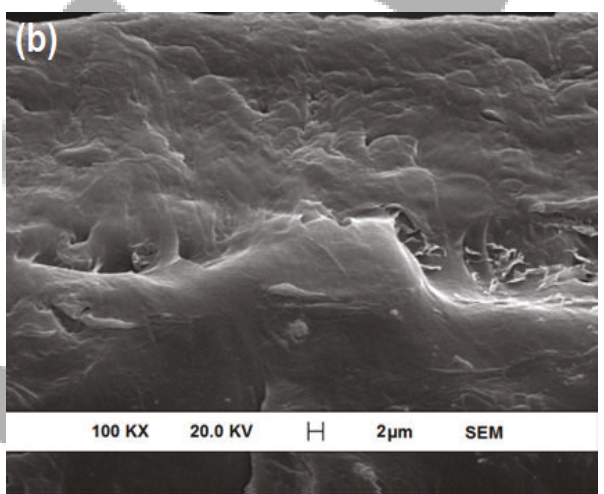

(b)

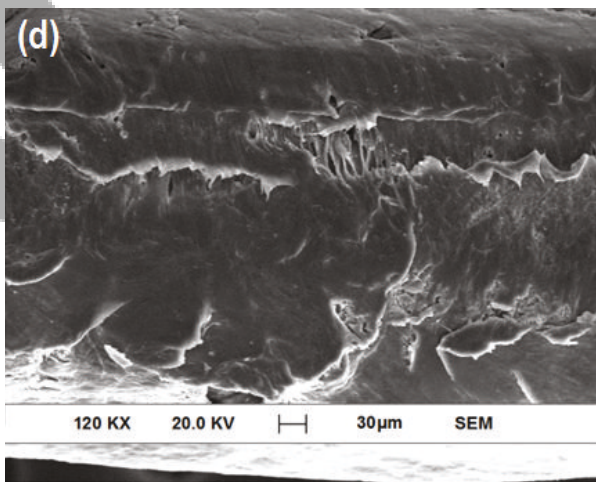

(d)

FIGURE 3: Scanning electron microscopy micrographs of ORS/PCL-Cs with 1.0, 3.0, 5.0, and 7.0 wt.\% (a)-(d) ORS, respectively.

decreased. This is evidence of the successful modification of the hydrophilic to hydrophobic properties of RS to hydrophobic [33].

In the FT-IR spectrum of PCL (Figure 5(b)), the peaks located at 2943,2863 , and $1723 \mathrm{~cm}^{-1}$ are attributed to stretching vibration of $-\mathrm{CH}_{2}$ and vibration of $-\mathrm{C}=\mathrm{O}$ bonds, respectively. The peak at $1167 \mathrm{~cm}^{-1}$ is related to $\mathrm{C}-\mathrm{O}$ stretching [34].

No new peak appeared to show chemical interaction between the functional groups of fiber and PCL, but the intensity of peaks in ORS/PCL-Cs is decreased with the increase of ORS content from 1.0 to $7.0 \mathrm{wt} \%$ compared to PCL. This is due to the presence of ODA in the modified rice straw and formation of ORS/PCL-Cs.

According to the above results it can be seen in Figure 6 in which ODA was adsorbed on the RS surface through hydrogen bonding between the $-\mathrm{OH}$ groups available in RS and the amine group present in the ODA. After that a temporary dipole moment creates between the PCL and ODA which has positive and negative charges towards ODA and PCL, respectively, so these positive charges can be attracted 


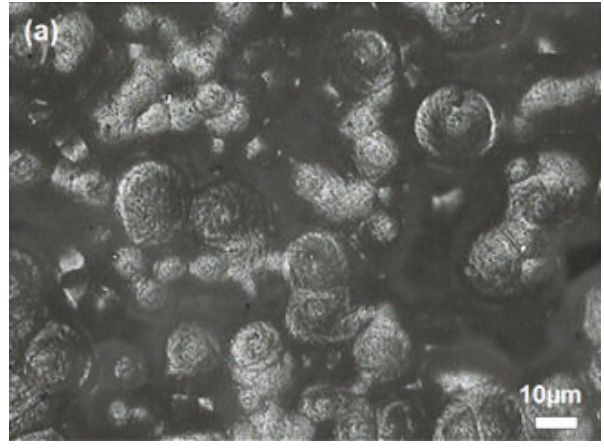

(a)

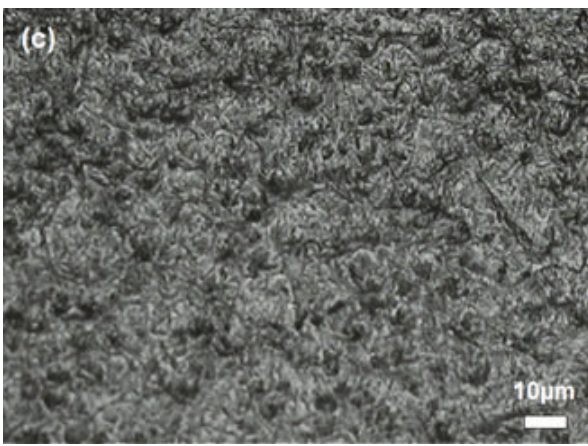

(c)
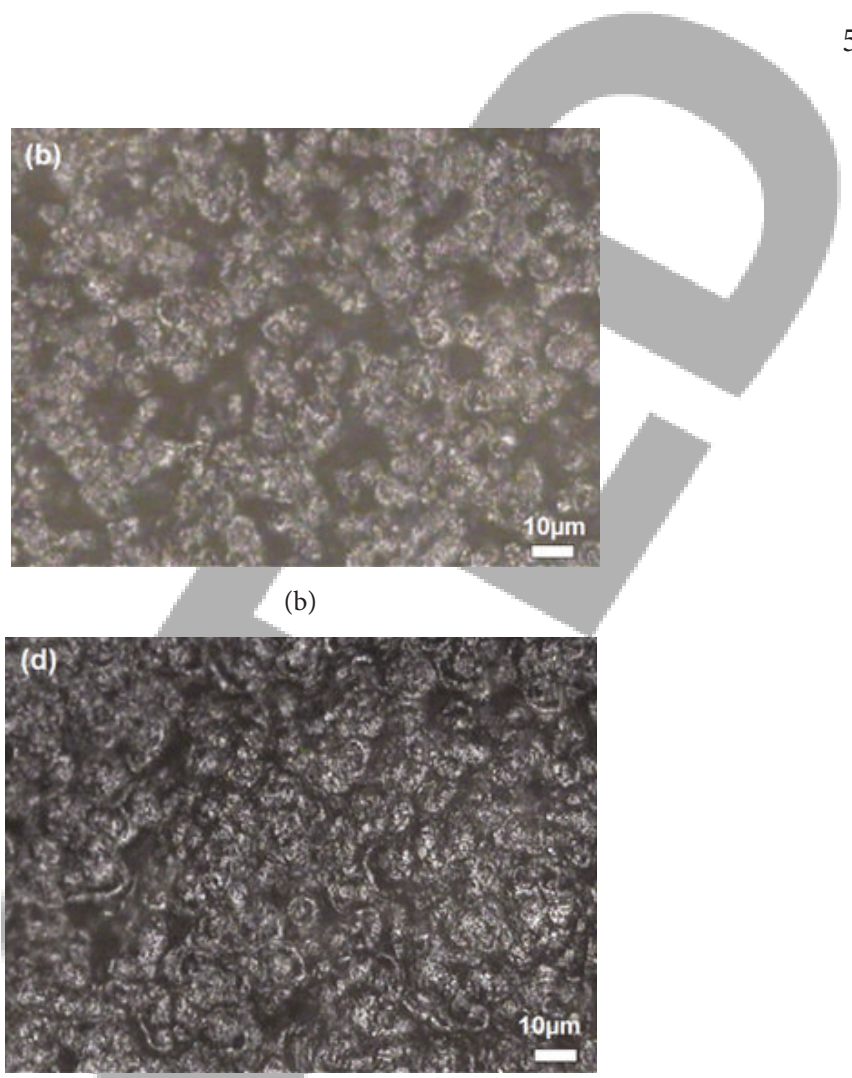

(d)

FIGURE 4: EOM images of ORS/PCL-Cs with 1.0, 3.0, 5.0, and 7.0 wt.\% ORS (a)-(d), respectively.

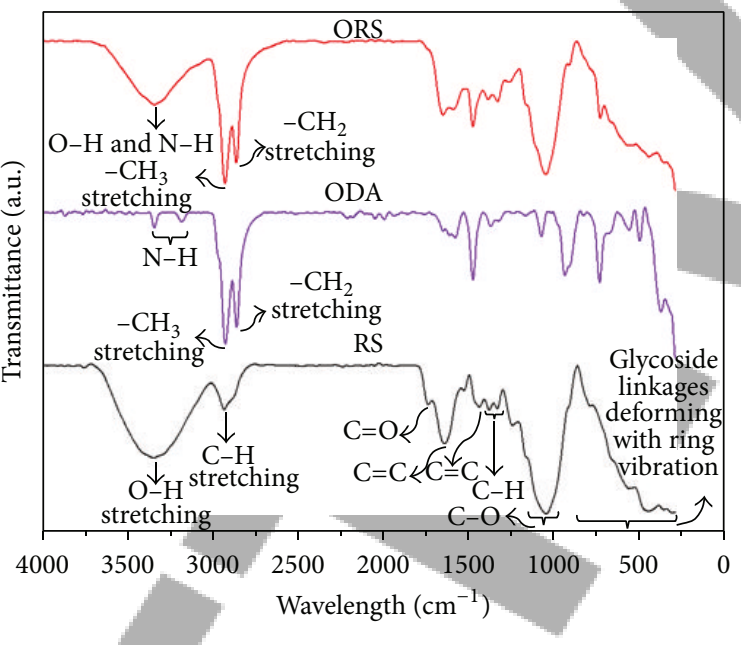

(a)

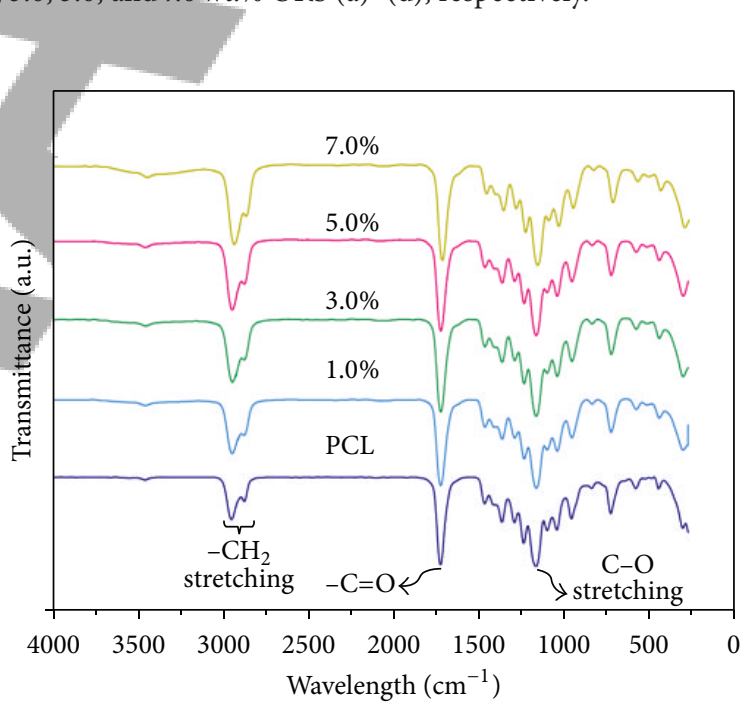

(b)

FIGURE 5: Fourier transforms infrared spectra of RS, ODA, and ORS (a), PCL, and composites with 1.0, 3.0, 5.0, and 7.0 wt.\% ORS (b).

to each other. It shows that the interaction between RS, ODA, and PCL is physical interaction.

3.4. Thermogravimetric Analysis. The thermal stabilities of all components were measured by TGA. Because thermal decomposition can lead to defunctionalization RS, TGA was used to determine the effect of content ORS in weight loss of the composites. Figure 7(a) shows typical TGA thermograms of the PCL, ORS/PCL-Cs, ORS, and degradation temperature 


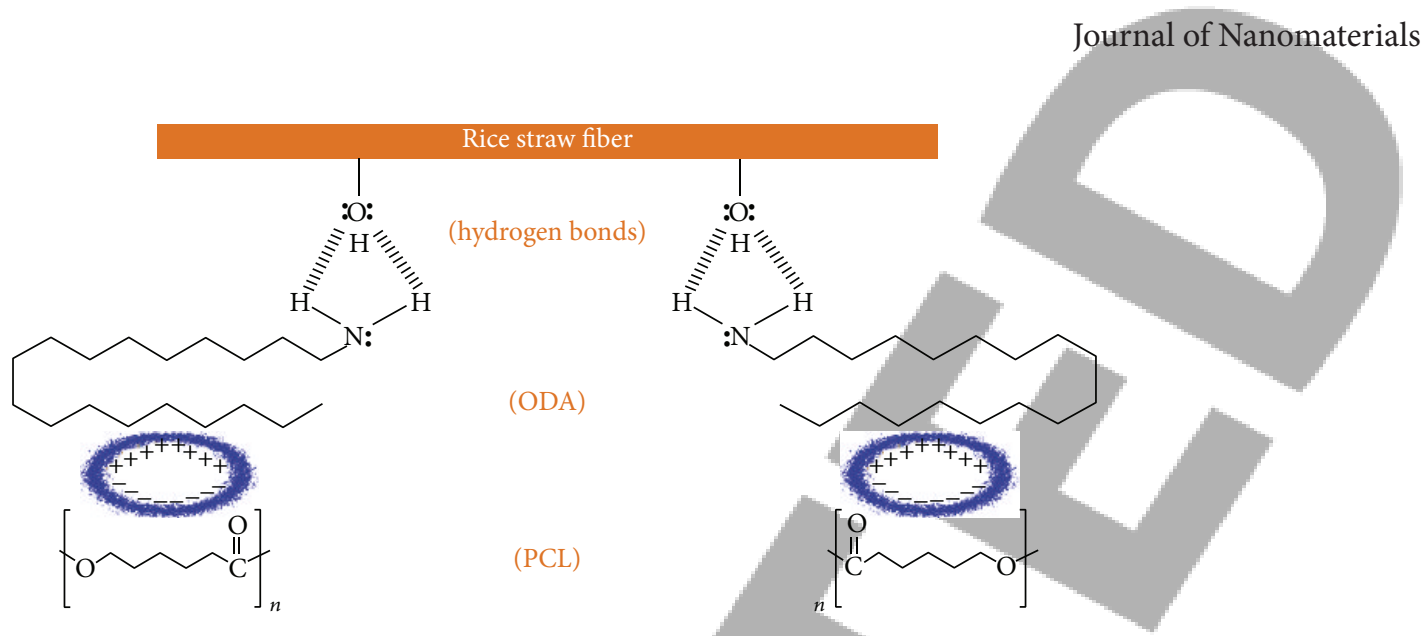

FIGURE 6: Schematic illustration of preparation of ORS/PCL-Cs.
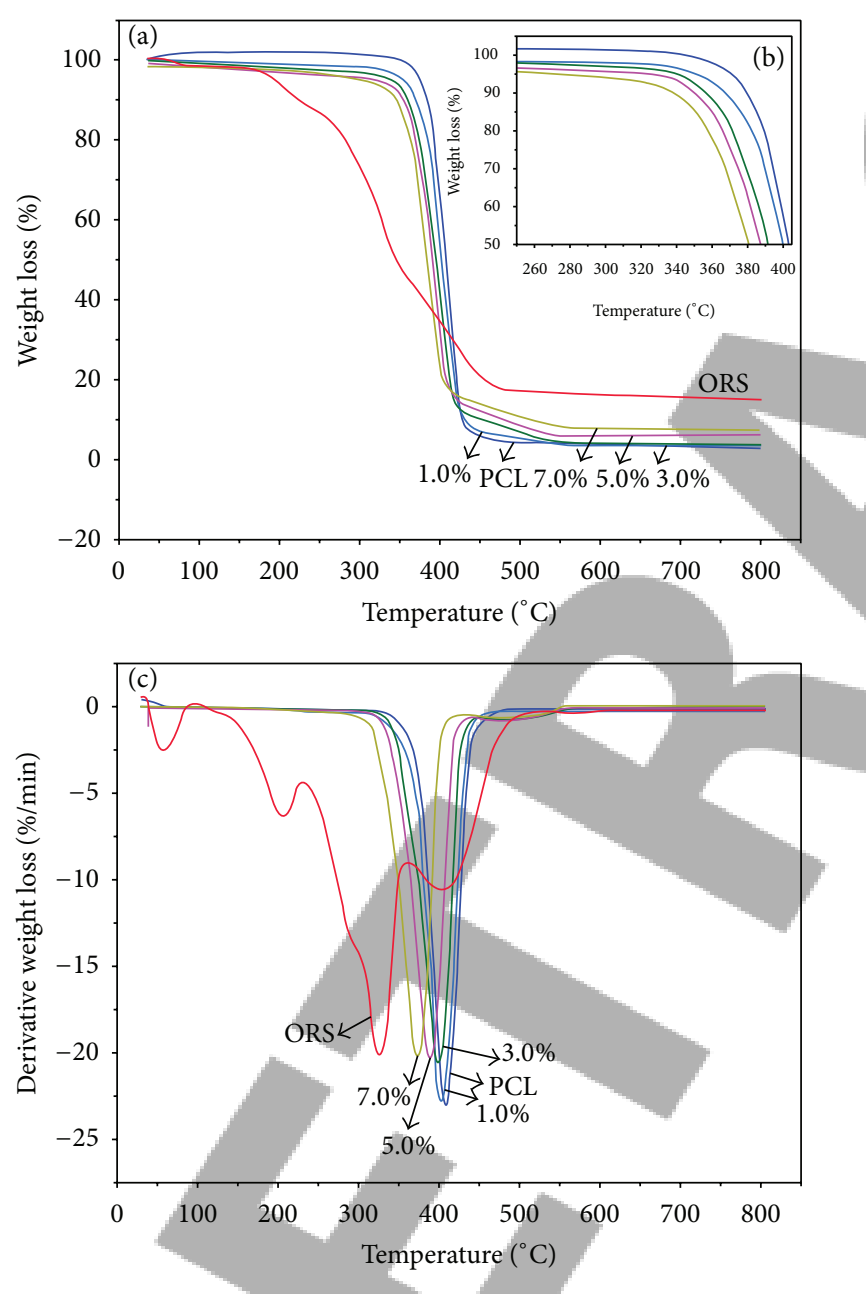

FIGURE 7: TGA (a), (b) and DTG (c) thermograms of PCL, ORS, and ORS/PCL-Cs, with 1.0, 3.0, 5.0, and 7.0 wt.\% ORS.

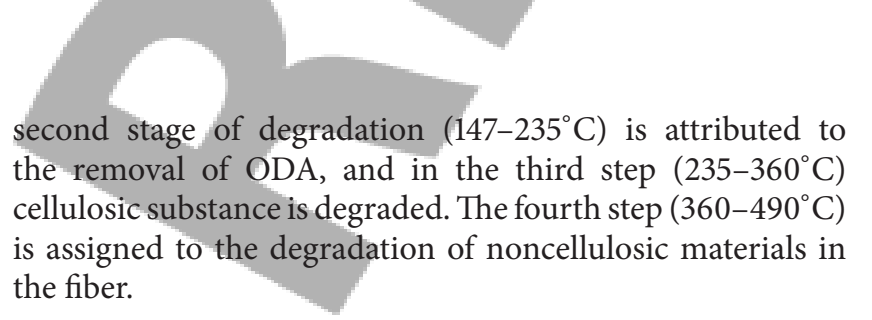

TGA thermogram of composites with 3.0, 5.0, and $7.0 \mathrm{wt}$ \% ORS indicated two stages of degradation; the first stage, that is, between $260-400^{\circ} \mathrm{C}$, is assigned to the degradation of ORS and in the second stage, between 405$550^{\circ} \mathrm{C}$, polymeric matrix is degraded. It was shown in the TGA thermograms that the ORS/PCL-Cs show lower onset temperature for the thermal degradation than neat PCL. PCL exhibits an onset temperature of $310.97^{\circ} \mathrm{C}$, which decreased to $286.27,300.86,304.61$, and $309.08^{\circ} \mathrm{C}$ when $7.0,5.0,3.0$, and $1.0 \mathrm{wt} . \%$ of ORS, respectively, incorporated into the PCL. The lower onset temperature for the thermal degradation of composites compared to PCL is due to the low thermal stability of ORS [11]. It can be seen that the ORS/PCLCs in higher loading percentages of ORS have lower onset temperature; it shows that thermal stability decreased with increasing ORS content. This result may be attributed to a looser PCL structure caused by RS-induced expansion [36]. By comparing thermal stability of ORS/PCL-Cs with RS/PCL-Cs, the RS/PCL-Cs had a lower thermal stability than the ORS/PCL-Cs (the results not shown).

The DTG curve of PCL in Figure 7(c) shows a single peak at $409.04^{\circ} \mathrm{C}$. This decomposition corresponds to the complete dissolution of PCL. The DTG curve of ORS shows four peaks at $60.09,204.38,324.77$, and 405.45. The DTG curves show that the $\mathrm{T}_{\max }$ of the composites which correspond to the maximum degradation rate is lower, that is, $402.27^{\circ} \mathrm{C}$, $400.10^{\circ} \mathrm{C}, 387.76^{\circ} \mathrm{C}$, and $372.95^{\circ} \mathrm{C}$, for PCL containing 1.0 , $3.0,5.0$, and $7.0 \mathrm{wt} . \%$ of ORS, respectively, compared to the PCL. The decrease in the degradation temperature is due to the ORS's low thermal stability which results in the heat transmission and raises the diffusion of volatile products released by substances. Table 1 shows degradation temperature of ORS, PCL, and composites according to TGA and DTG.

\subsection{Mechanical Properties}

3.5.1. Tensile Strength. The tensile strength of the ORS/PCLCs was shown in Figure 8(a). It can be seen with increasing RS content that the tensile strength gradually decreases, except in ORS/PCL-Cs (5.0 wt.\%) that is probably caused by good dispersion of ORS into the matrix and intercalation of ORS 

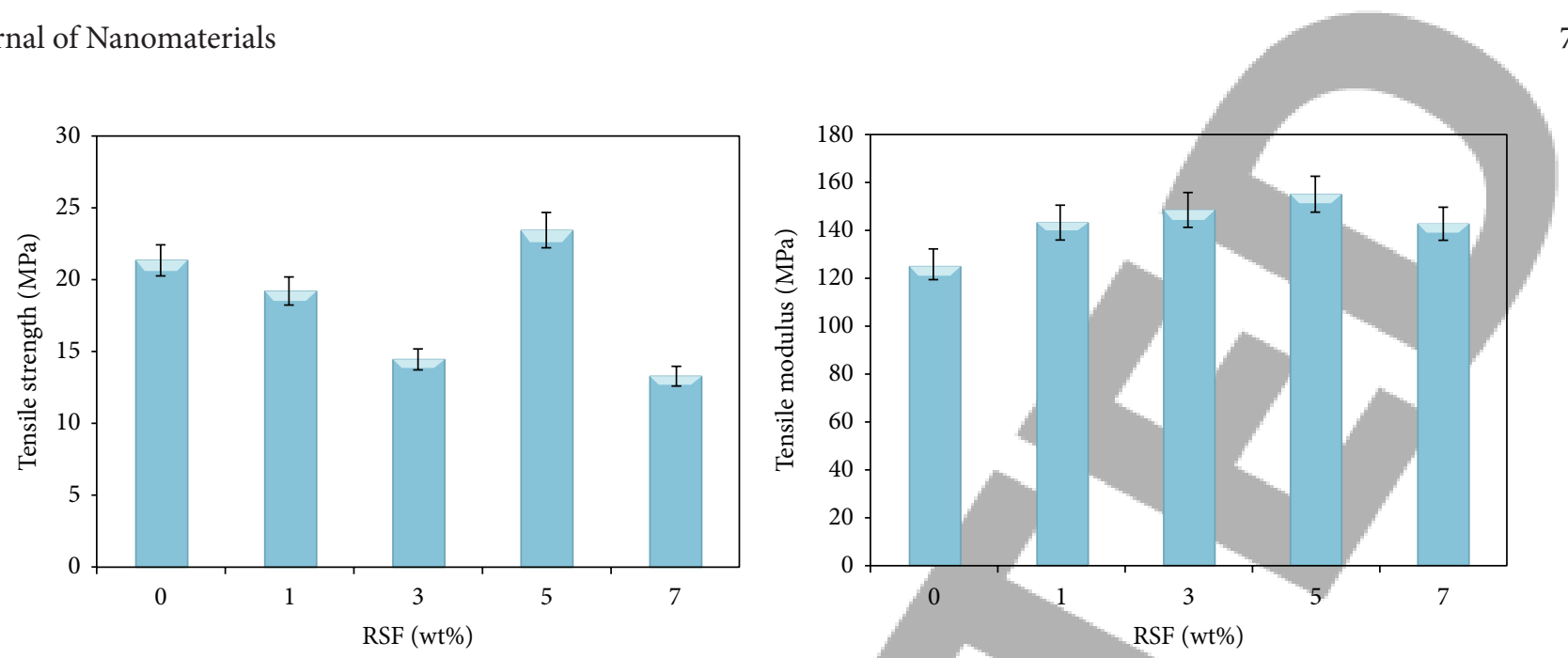

(a)

(b)

FIGURE 8: Tensile strength (a), tensile modulus (b), and elongation at break (c) of ORS/PCL-Cs in different wt.\% of ORS.

TABLE 1: Degradation temperature at 5.0, 10.0, 50.0, and 80.0\% fiber degradation, obtained by TGA and DTG.

\begin{tabular}{|c|c|c|c|c|c|c|}
\hline Sample & $\begin{array}{l}T_{5} \% \\
\left({ }^{\circ} \mathrm{C}\right) \\
\end{array}$ & $\begin{array}{r}T_{10} \% \\
\left({ }^{\circ} \mathrm{C}\right) \\
\end{array}$ & $\begin{array}{r}T_{50} \% \\
\left({ }^{\circ} \mathrm{C}\right)\end{array}$ & $\begin{array}{r}T_{80} \% \\
\left({ }^{\circ} \mathrm{C}\right) \\
\end{array}$ & $\begin{array}{l}T_{\max } \\
\left({ }^{\circ} \mathrm{C}\right)\end{array}$ & $\begin{array}{c}\text { Residue at } 500^{\circ} \mathrm{C} \\
(\%)\end{array}$ \\
\hline ORS & 196.38 & 222.55 & 343.11 & 452.60 & 404.45 & 17.2 \\
\hline PCL & 370.83 & 380.01 & 404.16 & 418.50 & 409.04 & 5.0 \\
\hline $1.0 \%$ & 351.75 & 367.95 & 400.57 & 413.62 & 402.27 & 5.2 \\
\hline $3.0 \%$ & 348.86 & 356.29 & 393.07 & 409.08 & 400.10 & 6.3 \\
\hline $5.0 \%$ & 327.13 & 349.94 & 388.53 & 404.37 & 387.76 & 8.1 \\
\hline $7.0 \%$ & 306.75 & 343.13 & 381.72 & 400.15 & 372.95 & 10.9 \\
\hline
\end{tabular}

with PCL. The inverse relation between tensile strength and ORS content might be due to the phase separation caused by the agglomeration of the ORS. The agglomeration of the ORS occurs as a consequence of not homogeneously distributed ORS in the matrix. The decrease in tensile strength indicates that there was no improvement in interaction between PCL and fiber. Thus, only $5.0 \mathrm{wt} . \%$ ORS is sufficient to enhance the tensile strength, and the highest tensile strength which was observed at $5.0 \mathrm{wt}$ \% ORS loading is $23.44 \mathrm{MPa}$.

In comparison with the tensile strength of RS/PCLCs it showed that the tensile strength of ORS/PCL-Cs is higher than RS/PCL-Cs. With addition of RS to the PCL the tensile strength of PCL decreased totally. It shows the poor compatibility between the RS and PCL.

3.5.2. Tensile Modulus. As shown in Figure 8(b) by adding filler content, ORS to the PCL, the tensile modulus remarkably improves for composites. The increase in the tensile modulus is possibly due to the restriction of the polymer chains from the interaction with the ORS surface [37]. Tensile modulus is a measure of the toughness of an elastic material and the growing tendency of the tensile modulus tests the 
behavior of the rigidity of exposures made of composite material. When these composites are subjected to tensile stress within the elastic range, the composites materials will not stretch a lot and they will behave like rigid composite products. The overall increase in the modulus implies the capability of the fiber to represent greater toughness to the composites [38].

3.5.3. Elongation at Break. Reduction in elongation at break accompanies with an increase in ORS content as shown in Figure 8(c). It demonstrates that ductility of the matrix gradually decreases with increasing ORS content. The lignocelluloses fibers such as RS are responsible for decreasing the elongation at break. PCL matrix supplies ductility while the RS shows brittle behavior with a subsequent decrease in stiffness of the composites material. Adding RS will interrupt the PCL segment mobility and therefore converting the composite to be more brittle as the amount of RS increased in the composites. Theoretically, low percentage of elongation at break of the composites indicates that composites are brittle or have low ductility [1].

\section{Conclusions}

ORS/PCL-Cs with different percentages loading of ORS were successfully prepared through a solution casting of PCL and ORS using ODA as a modifier of RS. The effect of different percentages loading of ORS into the PCL was studied. The optimum ORS loading with enhanced mechanical and thermal properties of PCL was $5.0 \mathrm{wt} . \%$ ORS. From XRD patterns, it can be inferred that the ORS/PCL-Cs show shift to lower value of $2 \theta$, and the intensity of peaks is decreased with the increase of ORS content from 1.0 to $7.0 \mathrm{wt} . \%$; this result indicated the formation of ORS/PCL-Cs. TGA thermogram shows that thermal stability decreased with increasing ORS content. FT-IR results show exhibited a decrease in intensity of peaks with the increase of ORS content from 1.0 to $7.0 \mathrm{wt} . \%$. In addition have been not founded no chemical interaction between PCL and ORS, and the interaction could be physical interaction as there is no new band or any significant shift compared to the PCL spectrum.

\section{Conflict of Interests}

The authors declare that there is no conflict of interests regarding the publication of this paper.

\section{Acknowledgments}

The authors thank University Putra Malaysia (UPM) for its financial support. The authors are also grateful to the staff of the Department of Chemistry UPM for their help in this research and to the Institute of Bioscience (IBS/UPM) for technical assistance.

\section{References}

[1] Y. Xie, C. A. S. Hill, Z. Xiao, H. Militz, and C. Mai, "Silane coupling agents used for natural fiber/polymer composites: a review," Composites A: Applied Science and Manufacturing, vol. 41, no. 7, pp. 806-819, 2010.

[2] A. Buzarovska, G. G. Bogoeva, A. Grozdanov, M. Avella, G. Gentile, and M. Errico, "Potential use of rice straw as filler in eco-composite materials," Australian Journal of Crop Science, vol. 1, no. 2, pp. 37-42, 2008.

[3] R. Chandra and R. Rustgi, "Biodegradable polymers," Progress in Polymer Science, vol. 23, no. 7, pp. 1273-1335, 1998.

[4] Y. Wang, M. A. Rodriguez-Perez, R. L. Reis, and J. F. Mano, "Thermal and thermomechanical behaviour of polycaprolactone and starch/polycaprolactone blends for biomedical applications," Macromolecular Materials and Engineering, vol. 290, no. 8, pp. 792-801, 2005.

[5] A. Cao, T. Okamura, K. Nakayama, Y. Inoue, and T. Masuda, "Studies on syntheses and physical properties of biodegradable aliphatic poly(butylene succinate-co-ethylene succinate)s and poly(butylene succinate-co-diethylene glycol succinate)s," Polymer Degradation and Stability, vol. 78, no. 1, pp. 107-117, 2002.

[6] M. Eili, K. Shameli, N. A. Ibrahim, and W. M. Z. Wan Yunus, "Degradability enhancement of poly(lactic acid) by stearate$\mathrm{Zn}_{3} \mathrm{Al} \mathrm{LDH}$ nanolayers," International Journal of Molecular Sciences, vol. 13, no. 7, pp. 7938-7951, 2012.

[7] M. B. Ahmad, M. Y. Tay, K. Shameli, M. Z. Hussein, and J. J. Lim, "Green synthesis and characterization of silver/chitosan/polyethylene glycol nanocomposites without any reducing agent," International Journal of Molecular Sciences, vol. 12, no. 8, pp. 4872-4884, 2011.

[8] K. Shameli, M. B. Ahmad, S. D. Jazayeri, P. Shabanzadeh, P. Sangpour, and H. Jahangirian, "Investigation of antibacterial properties silver nanoparticles prepared via green method," Chemistry Central Journal, vol. 6, article 1, 2012.

[9] C. P. Liau, M. B. Ahmad, K. Shameli et al., "Preparation and characterization of polyhydroxybutyrate/polycaprolactone nanocomposites," The Scientific World Journal, vol. 2014, Article ID 572726, 9 pages, 2014.

[10] Y. L. Pak, M. B. Ahmad, K. Shameli, W. M. Z. Wan Yunus, N. A. Ibrahim, and N. Zainuddin, "Mechanical and morphological properties of poly-3-hydroxybutyrate/poly(butyleneadipateco-terephthalate)/layered double hydroxide nanocomposites," Journal of Nanomaterials, vol. 2013, Article ID 621097, 9 pages, 2013.

[11] M. B. Ahmad, J. J. Lim, K. Shameli, N. A. Ibrahim, and M. Y. Tay, "Synthesis of silver nanoparticles in chitosan, gelatin and chitosan/gelatin bionanocomposites by a chemical reducing agent and their characterization," Molecules, vol. 16, no. 9, pp. 7237-7248, 2011.

[12] K. Shameli, M. B. Ahmad, W. M. Z. Wan Yunus, N. A. Ibrahim, M. Jokar, and M. Darroudi, "Synthesis and characterization of silver/polylactide nanocomposites," World Academy of Science, Engineering and Technology, vol. 64, pp. 28-32, 2010.

[13] R. Khandanlou, M. B. Ahmad, K. Shameli, and K. Kalantari, "Investigation of the role of reductant on the size control of $\mathrm{Fe}_{3} \mathrm{O}_{4}$ nanoparticles on rice straw," BioResources, vol. 9, no. 1, pp. 642-655, 2014.

[14] R. Khandanlou, M. B. Ahmad, K. Shameli, and K. Kalantari, "Synthesis and characterization of rice straw $/ \mathrm{Fe}_{3} \mathrm{O}_{4}$ nanocomposites by a quick precipitation method," Molecules, vol. 18, no. 6, pp. 6597-6607, 2013.

[15] M. B. Ahmad, K. Shameli, W. M. Z. Wan Yunus et al., "Synthesis and antibacterial activity of silver/montmorillonite nanocomposites," Research Journal of Biological Sciences, vol. 4, no. 9, pp. 1032-1036, 2009. 
[16] K. Shameli, M. B. Ahmad, E. A. J. Al-Mulla, P. Shabanzadeh, and S. Bagheri, "Antibacterial effect of silver nanoparticles on talc composites," Research on Chemical Intermediates, pp. 1-13, 2013.

[17] K. Shameli, M. B. Ahmad, S. D. Jazayeri et al., "Investigation of antibacterial properties silver nanoparticles prepared via green method," Chemistry Central Journal, vol. 6, no. 1, article 73, 2012.

[18] M. B. Ahmad, K. Shameli, W. M. W. Wan Yunus, N. A. Ibrahim, A. A. Hamid, and M. Zargar, "Antibacterial activity of silver/clay/chitosan bionanocomposites," Research Journal of Biological Sciences, vol. 4, no. 11, pp. 1156-1161, 2009.

[19] M. B. Ahmad, J. J. Lim, K. Shameli, N. A. Ibrahim, M. Y. Tay, and B. W. Chieng, "Development of a novel 96-microwell assay with high throughput for determination of olmesartan medoxomil in its tablets," Chemistry Central Journal, vol. 6, no. 1, article 1, 2012.

[20] K. Shameli, M. B. Ahmad, E. A. J. Al-Mulla et al., "Green biosynthesis of silver nanoparticles using Callicarpa maingayi stem bark extraction," Molecules, vol. 17, no. 7, pp. 8506-8517, 2012.

[21] M. Zargar, K. Shameli, G. R. Najafi, and F. Farahani, "Plant mediated green biosynthesis of silver nanoparticles using Vitex negundo L. extract," Journal of Industrial and Engineering Chemistry, 2014.

[22] K. Oksman, A. P. Mathew, D. Bondeson, and I. Kvien, "Manufacturing process of cellulose whiskers/polylactic acid nanocomposites," Composites Science and Technology, vol. 66, no. 15, pp. 2776-2784, 2006.

[23] A. Sorrentino, G. Gorrasi, and V. Vittoria, "Potential perspectives of bio-nanocomposites for food packaging applications," Trends in Food Science and Technology, vol. 18, no. 2, pp. 84-95, 2007.

[24] M. Wollerdorfera and H. Baderb, "Influence of natural fibres on the mechanical properties of biodegradable polymers," Industrial Crops and Products, vol. 8, no. 2, pp. 105-112, 1998.

[25] R. G. Raj, B. V. Kokta, F. Dembele, and B. Sanschagrain, "Compounding of cellulose fibers with polypropylene. Effect of fiber treatment on dispersion in the polymer matrix," Journal of Applied Polymer Science, vol. 38, no. 11, pp. 1987-1996, 1989.

[26] M. Kazayawoko, J. J. Balatinecz, and L. M. Matuana, "Surface modification and adhesion mechanisms in woodfiberpolypropylene composites," Journal of Materials Science, vol. 34, no. 24, pp. 6189-6199, 1999.

[27] Y. Zhaoa, J. Qiua, H. Feng, M. Zhang, L. Lei, and X. Wu, "Improvement of tensile and thermal properties of poly(lactic acid) composites with admicellar-treated rice straw fiber," Chemical Engineering Journal, vol. 173, pp. 659-666, 2011.

[28] X. Chen, J. Yu, Z. H. Zhang, and C. Lu, "Study on structure and thermal stability properties of cellulose fibers from rice straw," Carbohydrate Polymers, vol. 85, no. 1, pp. 245-250, 2011.

[29] L. Qin, J. Qiu, M. Liu et al., "Mechanical and thermal properties of poly(lactic acid) composites with rice straw fiber modified by poly(butyl acrylate)," Chemical Engineering Journal, vol. 166, no. 2, pp. 772-778, 2011.

[30] R. C. Sun, J. Tomkinson, P. L. Ma, and S. F. Liang, “Comparative study of hemicelluloses from rice straw by alkali and hydrogen peroxide treatments," Carbohydrate Polymers, vol. 42, no. 2, pp. 111-122, 2000.

[31] X. F. Sun, F. Xu, R. C. Sun, P. Fowler, and M. S. Baird, "Characteristics of degraded cellulose obtained from steam-exploded wheat straw," Carbohydrate Research, vol. 340, no. 1, pp. 97-106, 2005.
[32] W. Cao, Z. Dang, X. Zhoua et al., "Removal of sulphate from aqueous solution using modified rice straw: preparation, characterization and adsorption performance," Carbohydrate Polymers, vol. 85, pp. 571-577, 2011.

[33] M. Z. Abdul Hamid, N. A. Ibrahim, W. Md Zin Wan Yunus, K. Zaman, and M. Dahlan, "Effect of grafting on properties of oil palm empty fruit bunch fiber reinforced polycaprolactone biocomposites," Journal of Reinforced Plastics and Composites, vol. 29 , no. 18, pp. 2723-2731, 2010.

[34] J. Han, C. J. Branford-White, and L. Zhu, "Preparation of poly( $\varepsilon$ caprolactone)/poly(trimethylene carbonate) blend nanofibers by electrospinning," Carbohydrate Polymers, vol. 79, no. 1, pp. 214-218, 2010

[35] S. S. Ray and S. M. Bousmina, "Biodegradable polymers and their layered silicate nanocomposites: in greening the 21st century materials world," Progress in Materials Science, vol. 50, no. 8, pp. 962-1079, 2005.

[36] C. S. Wu and H. T. Liao, "Polycaprolactone-based green renewable ecocomposites made from rice straw fiber: characterization and assessment of mechanical and thermal properties," Industrial and Engineering Chemistry Research, vol. 51, no. 8, pp. 3329-3337, 2012.

[37] Y. Y. Then, N. A. Ibrahim, and M. Z. W. Yunus, "Enhancement of tensile strength and flexibility of polycaprolactone/tapioca starch blends by octadecylamine modified clay," Journal of Polymers and the Environment, vol. 19, no. 2, pp. 535-539, 2011.

[38] S. Siyamak, N. A. Ibrahim, S. Abdolmohammadi, W. M. Z. B. W. Yunus, and M. Z. A. B. Rahman, "Enhancement of mechanical and thermal properties of oil palm empty fruit bunch fiber poly(butylene adipate-co-terephtalate) biocomposites by matrix esterification using succinic anhydride," Molecules, vol. 17, no. 2, pp. 1969-1991, 2012. 